\title{
THEATRE AND PERSONA: CELEBRITY AND TRANSGRESSION
}

\author{
MARY LUCKHURST \& SANDRA MAYER
}

Theatre, with its focus on live performance and the particular interest it places on the performer as creative agent, undoubtedly brings a distinctive set of enriching perspectives to the field of persona studies, which has often acknowledged its debt to performance studies and theories of performativity (see, for instance, Marshall \& Barbour 2015). Despite some notable forays into the area of persona and (live) artistic performance made by scholars in this journal (see, for instance, Piper 2015; Colby 2015; D'Cruz 2015), work that specifically addresses the multifaceted uses and disuses of persona in theatre and its often radically transgressive potential is still conspicuously under-represented in a vibrant and swiftly expanding field. As guest editors of this special issue for Persona Studies, we are delighted to make a substantial intervention in bringing some of the theories and practices of theatre studies to persona studies. Likewise, the lens of persona studies concentrates analysts of theatre on interrogations that are fundamental to the discipline and to advancements in the notoriously difficult articulation of acting and the embodied performance of self and other.

This special issue focuses mainly on performers and writers and also extends to writerperformers and writer-directors. All of the essays break new ground and two of them address persona in relation to objects and institutional materialities and complexities. Playwrights, directors, designers, artistic directors, and producers cultivate their public personas (in theatre studies, we would say personaei) just like other creatives, often transforming themselves into branded celebrities in the process, but the performer is of quite unique fascination because the performer's body - face, voice, stance, movement, and gesture - is itself the material of artistic form and expression. In theatre it is the actor's body that creates persona live on-stage for audiences to respond to directly. Actors of live performance and acting as theory and practice are fundamental to conceptualising the performance of real and fictional selves and offer significant perspectives to persona studies. Dominant western actor training practices still focus on the studied creation of the appearance of spontaneity and, of course, the trained actor brings that embodied knowledge to the creation of different staged selves both for theatre and film roles and in the construction of different public selves in interview, in a memoir, or on social media. Actors have shaped the techniques and practices that inform persona construction but in the theatre industry itself this particular craft has often been obscured by a focus on the publicity machines that emphasise the magical and charismatic, and inspiration by the mystical and divine.

In screen and media studies, the extraordinary transformation that great actors can effect and the illusions that they conjure are primarily investigated through theories of reception, Freudian approaches, and the prism of stardom and celebrity (see, for instance, Dyer 1979 \& 1986; Gledhill 1991; Shingler 2012; Marcus 2019). In theatre studies, the focus is placed on theories of presence, concentration, and energy (Chaikin 1991; Goodall 2008; Power 2008), which, in some cases, productively intersect with celebrity studies and its perspective on charismatic performance (see especially Roach 2007; Giloi \& Berenson 2010). Yet, these approaches have not been sufficiently in dialogue with each other despite the fact that many celebrity performers work across theatre, film, and television and also create and transmit 
identity through a wide range of digital and traditional media. The study of persona offers one way of bridging this theoretical gap.

The concept of persona is related to the idea of the theatrical mask as a strategic construction of an identity that is complexly metatheatrical and performed. For Marshall, Moore, and Barbour, persona is "still attached to the concept of the mask, a layer, or adornment used to obscure the underlying features of the performer, providing a new surface upon which to inscribe a public identity" (Marshall, Moore \& Barbour 2020, p. 21). For theatre theorists the relationship between the performative and the real is understood as more contested and contradictory because live embodiment is a complicating factor that is absent from screen and digital media. The 'underlying features' of the performer are not necessarily deemed to be more readable, distinct or more authentic than the fictional role being played: in theatre they are likely to be read more playfully since live staging encourages bolder imaginative leaps and a greater suspension of disbelief. Furthermore, in theatre, mask is not always conceived in the literal sense of a disguise or adornment which might hide or obscure, but also as something indivisible and embodied that can be deployed to stage revelations of both self and role. Actor Michael Redgrave's famous formulation of face and mask bears this out:

The unmistakable stamp of an actor's personality or genius is always to be detected through whatever mask he has created for himself. Irving unmistakably remained Irving and Olivier, though frequently physically unrecognisable for several minutes, remained Olivier. This leads us to what for centuries - indeed since the time when the nature of acting was first discussed - has been the heart of the mystery. The crux of the paradox. Is it mask or face? In my opinion the two cannot be separated. Without the technique and discipline of mask, the face would not be visible. (Redgrave 1958, p. 27)

In the celebrity performer's life, the stage role and other public roles and appearances are frequently conflated and read across and into one another. "A face is such a volatile thing", Sir Ian McKellen has observed, and in seeking to capture or represent another or even play oneself (as McKellen did in Ricky Gervais's Extras), "actors are on a hiding to nothing" (qtd in Cantrell \& Luckhurst 2010, p. 100). To his adult audiences, McKellen argues, he is always the branded persona of Ian McKellen playing someone else (Cantrell \& Luckhurst 2010, p. 100) although younger audiences, of course, 'know' McKellen through the character and persona of Gandalf in the blockbuster adaptations of The Hobbit and Lord of the Rings as well as of Magento in the $X$-Men film series and might be unaware of McKellen's other stage and film personas. McKellen's celebrity persona brand is thus one that is complexly and curiously shaped by roles that have attained iconic status in both classical Shakespearean stage drama and popular film culture.

Persona studies has drawn substantially from the complex interplay of screen, media, communication, star and celebrity studies, which are disciplines that tend to treat the actor or actress as the object of commodification and media appropriation and (often too readily) assume that they have limited negotiating control over the construction of their on- and offscreen personas. As Pam Cook has argued, celebrity screen performance "is usually placed on the side of entertainment rather than art and is regarded as motivated by vested corporate interests as well as of the stars themselves" (Cook 2012, p. 74). Rightly, Cook points out that "comparatively little attention has been paid to the details of celebrity performance skills or the conventions of the modes in which they appear" (Cook 2012, p. 74). Despite recent revaluations of celebrity agency (see, especially, York 2013) that have begun to break up the traditional dichotomy of production and consumption underlying much celebrity theory, the craft of the performer in screen and star studies is still decidedly under-appreciated. This has become a 
significant problem because it has often marginalised the actor's voice, wrongly represented the performer's body as an empty vessel, and misrepresented the complex labour of creating screen roles, particularly in the case of women (Luckhurst 2019, pp. 72-100). Historically, theatre studies has also suffered serious methodological problems in relation to discourses in circulation about celebrity actresses and their performance, and both theatre and film theorists have frequently sidelined persona construction by performers who cultivate artistic craft, business acumen, managerial excellence, and commercial flair. Many celebrity actresses have found that persona construction around labour and production management is erased and substituted by personae constructed by critics and academics that privilege a typology promoting the sexual cypher, the domestic goddess, or the spousal appendage (Luckhurst 2019, pp. 72-100). A dialogue between theatre studies and the field of research into persona provides an interesting lens through which to examine the labour of acting and both the crafted and more indirect methods of persona production as well as the often tricky task of killing off an unwanted or redundant persona and reinventing a new one. Theatre studies also offers actortraining vocabularies that help to interrogate performers' private and public acts of persona construction/demolition and can offer enriching case studies where subjects lose control of their persona, are stifled by a persona that has outrun its purposes, or are denied the opportunity to negotiate a persona that is fed into the public realm without their involvement or consent.

Theatre has a long history of leftist political agitation, riot, and protest, and this issue also explores the associations of persona and transgression (Shalson 2017). The first two essays explore the changing personas of Shakespeare and how the iconic Shakespearean persona in England that Dame Judi Dench's own persona development has capitalised on is now under question as an imperial, exclusivist, and outdated construct. Marshall, Moore, and Barbour have contended that "persona studies is a technique that is fundamentally a study of agency" (Marshall et al 2015, p. 290), but how can we relate the concept of 'persona' to the mechanisms of posthumous appropriation and image construction and who are the agents in such cases?ii How do the sequence of Shakespearean personas created in film, musical, and television sitcom interrogate and shape the cultural iconicity of the most celebrated English-language poet and playwright of all times? Looking at twentieth- and twenty-first-century transmedial and transgeneric appropriations of Shakespeare as a comic character in popular culture, the eminent Shakespeare scholar Peter Holland takes mask as his starting point. The Shakespearean masks that form the subject of Holland's analysis, however, are not the result of the author's own strategic navigations of the public sphere; here, Shakespeare himself is recreated and remodelled through masks that offer up the playwright, actor, and shareholder of The King's Men company as "less a who than a what". These ironic postmodern constructs of Shakespeare deliberately topple an icon and point to the contemporary political crisis in England, suggesting that the demise of English imperialism, the isolationism and the instinct of the political classes in England to look backwards and to substitute action with imperialistic rhetoric, is also linked with Shakespearean personas that might no longer be relevant or politically viable. Holland examines a range of comic personas for Shakespeare, in particular, Ben Elton's successful television creation of Shakespeare in Upstart Crow. In Elton's sitcom, Shakespeare is reduced to a comically disempowered father and struggling businessman with a nightmare commute to London. His ideas are often crude, his failings are many, he appears anything but a genius and he is both likeable and annoying. Such comic personas, Holland asserts, are versions of Shakespeare intimating tropes which are familiar to us from celebrity discourses: Shakespeare as a weary celebrity irked by over-zealous fans; Shakespeare as a boorish, vulgar rockstar; and Shakespeare as a disappointingly ordinary human being whose work continues to bore and alienate legions of schoolchildren around the world. This sequence of masks or, as Holland calls 
it, a "mise en abyme of personas", melds into an aggregate of cultural performances that both fashion and call into question Shakespeare's iconic status in the cultural imaginary. Ultimately, the ironic Shakespearean masks created in the absence of the 'real' individual and his 'authentic' self, Holland suggests, are masks through which respective cultures are able to scrutinise themselves.

The ways in which Shakespeare and the cultural capital partly accrued through this succession of Shakespearean masks are strategically employed in the persona-building processes of contemporary theatrical icons, elevating them to the status of a national institution themselves, is explored by Sophie Duncan in her article on Judi Dench. Duncan explores reinventions of Dench's professional persona in the twenty-first century. One of England's bestloved actresses, Dench has made careful use of Shakespearean roles to take new directions in her theatrical career and thus shape and revise her persona construction as an ageing female performer. 'Ghosted' by a long line of celebrity actresses, these role choices have resulted in a collusion of on- and offstage personas that feed on such attributed qualities as sincerity, authenticity, and integrity (Carlson 2003). While consciously placing herself in a prestigious tradition of Shakespearean actresses on the English stage and drawing on their strategies of persona-creation, Dench has resisted the restrictive female continuation of Shakespearean performance genealogies by, for instance, refusing to play the Nurse in Romeo and Juliet, a decision that Duncan explains in the light of the part's history as a career-ending role for ageing star actresses. Ultimately, Dench's association with Shakespeare as a 'national poet' has not only augmented her significance as a much-loved stage icon and epitome of moral authority but has sparked discourses around national investments in the ageing female performer as a public persona that counteracts stereotypical notions of the older actress as sexually repugnant, infirm, and incapable of work (Luckhurst 2020).

One of Dench's long-term collaborators, the English playwright, screenwriter, and director David Hare, takes a similarly active part in the fashioning of his persona, albeit not only through his plays but, most notably, through his extra-theatrical interventions. Analysing Hare's autobiographically inflected lectures, essays, and his 2015 memoir The Blue Touch Paper, which all stage his field migrations between theatre and politics, Sandra Mayer demonstrates how Hare exploits the generic properties of non-fictional life-writing formats in order to try to build a composite authorial persona of politically engaged artist, social commentator, and public intellectual. As companion pieces that frame his artistic work, Hare's life-writing has served as an ideal vehicle for Hare's carefully cultivated 'autobiomyth' of the writer-propagandist who supposedly speaks from an outsider position that is informed by a Romantic tradition of strong authorship and connected with discourses that claim a truth value. Mayer demonstrates how Hare makes strategic use of autobiographical genre conventions which raise audience expectations of sincerity and authenticity, partly as a means of negotiating his career trajectory from the leftist theatrical fringe of the 1970 s to his status as a canonical playwright linked to England's male-dominated institutions of the cultural mainstream. Here, the proactive attempts to (re)invent his authorial persona, to justify his politics, and to try and secure his legacy in English theatre come in response to the need to find new relevance in a swiftly transforming post-Brexit age and a far more diverse theatre industry with which he is increasingly out of joint. Hare continues to argue for a persona that is politically transgressive but which few in the theatre industry find convincing.

The most detailed conceptualisations on the theory and practice of creating a stage persona reside in comedy studies and comic performance. Stand-up comedy is currently the most globally successful form of protest and human rights theatre and is inherently transgressive in its quest to address stigma, prejudice, and socio-cultural stereotypes 
(Luckhurst and Morin 2015). Two essays interrogate the transgressive potential of persona in live stand-up comedy, initiating an important disciplinary dialogue between persona studies, comedy studies, and human rights discourses. Mary Luckhurst examines what she calls the "meta-theatrics of persona creation" in the work of global stand-up icon Hannah Gadsby. In her article, she focuses on Gadsby's decision to assassinate her much-loved comic persona in her 2017 show Nanette, and to replace it with a new persona in order to expose the strategic operations of stand-up and their harmful consequences for the performer's mental health and emotional well-being. Luckhurst examines the tensions and blurred boundaries between onand offstage self, public brand, and stage persona, and Gadsby's contention that they often result in destructive patterns of self-deprecation, self-objectification, and reinforced prejudice that are predicated on a mutually abusive relationship between performer and audience. Viewed against the backdrop of a notoriously sexist comedy industry, Gadsby's breaching of stand-up protocols and her self-reflexive foregrounding of the making and unmaking of a comic persona are radically transgressive acts that render her unique in her professional risk-taking and virtuosity. Luckhurst coins the concept of 'meta-persona' as a lens through which to analyse Gadsby's demolition of her own successful comic persona and her criticism of the formal and thematic conventions of stand-up in order to negotiate a more honest relationship with her audiences. Ultimately, Gadsby's creative deconstruction goes hand in hand with the reinvention of a persona that is brutally honest, unapologetic, and uncompromising; a comic virtuoso who is in charge and refuses to make light of personal trauma for the gratification of her audiences and at the cost of her own mental health. Far from ending her career, her reinvented persona turned her into a global sensation. Even more importantly, her new persona has lived up to its full potential of protecting the performer, challenging and renewing stand-up as a form, educating her fanbase about the performance contract they are entering into, and altering audience perceptions of stand-up performance.

In a pioneering essay, Matt Hargrave examines how comic persona in stand-up performance gives rise to new discourses of lived experience about mental health, specifically conditions such as bipolar disorder, depression, and anxiety. Basing his study on the analysis of live events and empirical research, Hargrave argues that persona is key to mediating the relationship between the comedian, their material, and their audiences in what he refers to as a new "poetics of vulnerability". His inquiry into the concept of persona and its affective function reveals five ways in which persona operates in the context of stand-up that addresses mental health issues: as a protective device that allows the performer to voice and share their vulnerabilities; as an 'interruptive' element that remodels an existing persona construct and enables the articulation of revelatory content; as a theatrical conceit, a form of 'madding up', that complicates the notion of authenticity by blurring the lines between art and illness; as an emotional distancing effect that disrupts the binary between normative and non-normative, between what is commonly labelled 'sane' and 'mad'; and a way of expressing a sense of belonging in the social world. Hargrave demonstrates how studying the relationship of stand-up and persona yields valuable insights for both the fields of persona studies and the expanding field of performance and mental health. It casts a spotlight on the subjective experience of marginalised and stigmatised identities and contributes towards a revaluation of vulnerability as an aesthetic and social resource; a strength rather than a weakness, as it invites care and complicity and subverts binaries and fixed identities in marked opposition to neoliberal 'entrepreneurial subjectivity'.

The final two contributions to this special issue investigate the value of applying the concept of persona to non-human actors: three-dimensional material objects and larger cultural concepts, such as the archiving of performance artefacts and the institution of a theatre company as well as the historical persona of a building and its national heritage narratives. 
Emily Collett's article represents an important political intervention in both persona and theatre studies in considering the significance of material artefacts in the persona construction of the stage performer. It studies the materiality of the archived costume and the politically problematic narratives that can be generated by curators who may unwittingly embed a version of the performer's persona with which the performer in question does not identify. Collett focuses on Indigenous Australian actress Deborah Mailman's costume of Cordelia in Bell Shakespeare's 1998 production of King Lear, which is now housed in the Australian Performing Arts Collection in Melbourne. Collett raises poignant questions about to what extent the politically charged archival framing of material objects shapes the creation and production of persona, and how curatorial framings affect memorialisation processes. Elaborating on and contextualising the political implications of Mailman's archived costume, she explores the complex power dynamics of persona construction that come into play when an archived item presents a narrative that departs from, complicates, or even subverts the performer's current persona. Mailman's stage costume, in combination with whiteface make-up, worn by an Indigenous actress in a Shakespeare production for a white, mainstream Australian stage, is difficult not to read as a dubious attempt at a supposedly transgressive act by a white male director. It reads as an oppressive colonisation of the female Indigenous body that is at odds with Mailman's proactive cultivation of a public and professional persona that affirms her activist identity as a pioneering Indigenous actress in a white-dominated film and theatre industry. The archive does not house more recent costumes and artefacts of Mailman's and yet she is nationally celebrated not for the Shakespearean roles played at the beginning of her career but for her portrayal of strong, contemporary Indigenous women on film and television. Collett's research thus enriches our understanding that a narrative for persona can be generated by an object. She also highlights the politics of archival collecting, cataloguing, and curatorial framing and how those politics produce cultural value and articulate individual and collective identities through a specific persona suggested by an archived object at a particular historical moment.

The need for persona constructs to evolve and be continuously updated is also a central concern in Kirsty Sedgman's case study of the Bristol Old Vic, one of Britain's longest-running and most iconic theatres. Sedgman develops a terminology that allows us to identify and analyse the concept of institutional persona in relation to theatre. Drawing on Marshall's analytical category of VARP - value, agency, reputation, and prestige - she argues in favour of comprehending the theatre institution as a 'composite persona' whose cultural value emerges from the interplay of building, organisation, and event, and the reputational capital that adheres to each of these components. This 'composite persona' crucially relies on the interconnected, dynamic agency of individual personae involved in theatre management, production, performance, and criticism, as well as the audiences who engage with the different layers of the theatre institution over time. As Sedgman shows, legendary theatre institutions like the Bristol Old Vic that occupy a prominent place in the cultural imaginary demonstrate the need to mobilise a compound of individual and organisational personae in order to historically reimagine and re-invent their branded identities through shifting social and cultural frameworks. For institutions, in much the same way as for individuals, performative persona creation is essential to the acquisition of social and economic capital. In the case of the Bristol Old Vic, this is achieved by drawing on the theatre's prestigious architectural heritage, acclaimed performance traditions, and history of celebrity performers, artistic directors, playwrights, directors, and designers, and imaginatively aggregating these factors with a newly consolidated reputation of outward-looking aesthetic innovation.

This special issue offers numerous points of departure for theatre studies and persona studies to enter a productive dialogue, especially when it comes to re-interrogating the 
complexities and politics of the subject's agency in shaping their public personas and the ways in which this agency often jars with institutional frameworks, media appropriation, and audience perception. An in-depth exploration of persona-construction in theatre draws attention to an agency that is 'situated' (see Moran 2000, p. 10), "that operates alongside and even within structural forces and constraints" (York 2013, p. 1339), and that is closely tied to the labour and artistic craft of the performer, which holds an enormous potential for transgression, deconstruction, resistance, and activism. The actor's training and/or apprenticeship in the art of performance and their professionalised construction of different roles, guises and characters intimately informs practices of persona-construction both on and offstage and the vocabularies and theories of theatre studies together with those of persona studies offer a rich field for collaborative analysis.

\section{END NOTES}

i The plural 'personas' is the preferred usage according to the house style of the Persona Studies journal, but the alternative form 'personae' is often preferred by theatre scholars as it is true to the Latin etymological roots of the term, derived from theatrical practice, and is more suggestive of the nuances and tensions between the concepts of character, role, and self.

ii See, for instance, Mayer 2018 on the posthumous cross-cultural appropriation of Oscar Wilde's persona, which persistently underlies the production and reception of his dramatic oeuvre.

\section{WORKS CITED}

Cantrell, T. \& Luckhurst, M. 2010, Playing for Real: Actors on Playing Real People, Palgrave, London.

Carlson, M. 2003, The Haunted Stage: The Theatre as Memory Machine, University of Michigan Press, Ann Arbor.

Chaikin, J. 1991, The Presence of the Actor, Theatre Communications Group, New York.

Colby, S. 2015, 'Staging Nancy Cunard: The Question of Persona in Dramatizing her Life and Work', Persona Studies vol. 1, no. 2, pp. 14-30.

Cook, P. 2012, Nicole Kidman, Routledge, London.

D’Cruz, G. 2015, 'I Me Mine: Artistic Self/Artistic Persona', Persona Studies vol. 1, no. 1, https://ojs.deakin.edu.au/index.php/ps/article/view/456/445, retrieved 28 January 2020.

Dyer, R. 1979, Stars, British Film Institute, London.

Dyer, R. 1986/2004, Heavenly Bodies: Film Stars and Society, Routledge, Abingdon.

Giloi, E., \& Berenson, E., eds., 2010, Constructing Charisma: Celebrity, Fame, and Power in Nineteenth-Century Europe, Berghahn, New York.

Gledhill, C., ed. 1991, Stardom: Industry of Desire, Routledge, London.

Goodall, J. 2008, Stage Presence, Routledge, Abingdon.

Luckhurst, M. \& Morin, E., eds. 2015, Things Unspeakable: Theatre and Human Rights after 1945, Palgrave, London.

Luckhurst, M. 2019, 'Nicole Kidman: Transformation and the Business of Acting', Australasian Drama Studies, no. 75, pp.72-100.

Luckhurst, M. 2020, 'Great British Dames: Mature Actresses and their Negotiation of Celebrity in the $21^{\text {st }}$ Century', in J. Sewell \& C. Smout (eds), The Palgrave Handbook of the History of Women on Stage, Palgrave, London, pp. 250-272.

Marcus, S. 2019, The Drama of Celebrity, Princeton University Press, Princeton \& Oxford.

Marshall, P. D. \& Barbour, K. 2015, 'Making Intellectual Room for Persona Studies: A New Consciousness and Shifted Perspective', Persona Studies vol. 1, no. 1, pp. 1-12.

Marshall, P. D., Moore, C. \& Barbour, K. 2015, 'Persona as Method: Exploring Celebrity and the Public Self through Persona Studies', Celebrity Studies vol. 6, no. 3, pp. 288-305. 
Marshall, P.D., Moore, C. \& Barbour, K. 2020. Persona Studies: An Introduction, Wiley Blackwell, Oxford.

Mayer, S. 2018, Oscar Wilde in Vienna, Brill Rodopi, Amsterdam.

Moran, J. 2000, Star Authors: Literary Celebrity in America, Pluto Press, London.

Piper, M. 2015, 'Louie, Louis: The Fictional, Stage, and Auteur Personas of Louis C.K. in "Louie"', Persona Studies vol. 1, no. 1, pp. 13-24.

Power, C. 2008, Presence in Play: A Critique of Theories of Presence in the Theatre, Rodopi, Amsterdam.

Redgrave, M. 1958, Mask or Face? Reflections in an Actor's Mirror, Heinemann, London.

Roach, J. 2007, It, University of Michigan Press, Ann Arbor.

Shalson, L. 2017, Theatre and Protest, Palgrave, London.

Shingler, M. 2012, Star Studies: A Critical Guide, Bloomsbury, London.

York, L. 2013, 'Star Turn: The Challenges of Theorizing Celebrity Agency', The Journal of Popular Culture, vol. 46, no. 6, pp. 1330-1347. 